\title{
CINÉTICA DE LIBERAÇÃO DE POTÁSSIO EM PLANOSSOLO DO ESTADO DO RIO GRANDE DO SUL
}

\author{
POTASSIUM RELEASE FROM A PLANOSOL OF THE STATE OF RIO \\ GRANDE DO SUL, BRAZIL
}

\author{
Rosa Maria Vargas Castilhos ${ }^{1}$ Egon José Meurer ${ }^{2}$
}

\section{RESUMO}

\begin{abstract}
Ácidos orgânicos de baixo peso molecular têm sido utilizados em estudos de cinética de liberação de potássio em solos; estudos desta natureza possibilitam melhor entendimento da disponibilidade deste nutriente para as plantas. Este trabalho teve por objetivo investigar a cinética de liberação de potássio nas frações granulométricas de um Planossolo do Rio Grande do Sul, induzida pela ação do ácido oxálico. O estudo foi realizado com amostra superficial $(0-20 \mathrm{~cm})$ do horizonte A na qual foiquantificado o potássio liberado dos solos após equilíbrio com ácido oxálico 0,01mol $L^{-1}$ até 3.409 horas. O ácido oxálico induziu a liberação de potássio das frações areia, silte e argila, que decresceu na sequência silte > argila >areia. A descrição da cinética de liberação do potássio pela equação parabólica de difusão mostrou que o processo ocorreu, em duas fases para as frações areia e silte e em três fases para a fração argila, com taxas variando entre $0,65 \times 10^{-2} h^{-1}$ a 3,55 $\times 10^{-2} h^{-1}$. A quantidade de potássio liberada das frações representou somente $2,1 \%$ do $K$ total do Planossolo.
\end{abstract}

Palavras-chave: equação de difusão, potássio não trocável, arroz irrigado por inundação.

\section{SUMMARY}

Low molecular organic acids have been utilized in kinetic studies of potassium release from K-bearing minerals in soils; these studies can improve the knowledge about the availability of this nutrient to plants. This study was undertaken to investigate the kinetics of potassium release from a Planosol of the State of Rio Grande do Sul, Brazil. Sample of A horizon (0$20 \mathrm{~cm}$ ) were equilibrated with oxalic acid $0.01 \mathrm{~mol} \mathrm{~L}^{-1}$ up to 3.409 hours. Oxalic acid induced $K$ release from sand, silt and clay, that decreased in the sequence: silte > argila > sand. The parabolic diffusion equation showed that potassium release occurred in two phases for sand and silt, and in three phases for clay, at different rates, ranging from $0.65 \times 10^{-2} h^{-1}$ to $3.55 \times$
$10^{-2} h^{-1}$. The amount of potassium released from soil fractions, taking in account the amount released by each fraction and its percentage in the whole soil, were only $2.1 \%$ of total $\mathrm{K}$. The role of organic acids in affecting the potassium supplying power in tropical soils must be better studied.

Key words: diffusion equation, non-exchangeable potassium, flooded rice

\section{INTRODUÇÃO}

Estudos sobre cinética de liberação de potássio e sua relação com a disponibilidade e absorção pelas plantas permitem uma melhor compreensão da dinâmica de liberação desse nutriente do solo e podem fornecer subsídios para melhor adequação das recomendações de adubação. Nos últimos, anos foram conduzidos diversos estudos para quantificar as taxas de liberação de potássio de minerais fontes deste nutriente para as plantas Nestes estudos, foram utilizadas soluções salinas diluídas, tetrafenilborato de sódio e resinas trocadoras de cátions (MUNN et al. 1976, SIMARD et al., 1992; COX et al., 1996; MARTIN \& SPARKS, 1985; DHILON \& DHILON, 1990; MEURER \& ROSSO,1997). Ácidos orgânicos de baixo peso molecular, como o cítrico e o oxálico também têm sido utilizados em estudos de cinética de liberação de potássio em solos. Os ácidos orgânicos podem facilitar a intemperização de minerais pela formação de complexos orgânico-metálicos (TAM, 1986). Trabalhos têm demonstrado a ação destes ácidos na

\footnotetext{
${ }^{1}$ Engenheiro Agrônomo, Doutor, Professor do Departamento de Solos, Universidade Federal de Pelotas, CP 354, 96001-970, Pelotas-RS.

${ }^{2}$ Engenheiro Agrônomo, Doutor, Professor do Departamento de Solos, Universidade Federal do Rio Grande do Sul, CP 776, 90001-970, Porto Alegre-RS. Bolsista do CNPq. E-mail: egon.meurer@ufrgs.br. Autor para correspondência.
} 
dinâmica de liberação de potássio de minerais (SONG \& HUANG,1988), de solos (MEHTA $\boldsymbol{e t}$ al. 1995; SILVA et al., 1998 ), e de suas frações granulométricas (SIMARD $\boldsymbol{e t}$ al.,1992).

O cultivo do arroz irrigado por inundação é importante atividade agrícola e de significativa expressão econômica no Estado do Rio Grande do Sul. Estudos de calibração realizados com esta cultura nesse Estado mostraram que, em geral, não há relação entre o teor de potássio disponível no solo (extraído pelo método Mehlich-1) e o rendimento de grãos de arroz no campo (LOPES, 1989; MACHADO \& FRANCO, 1995; SIMONETE, 1998). Em dois planossolos, um chernossolo e um gleissolo, utilizados em cultivos com arroz irrigado por alagamento, foram identificados, nos horizontes A e B, minerais fontes de potássio, primários e secundários, que possivelmente podem explicar a ausência de respostas à adubação potássica nesses solos (CASTILHOS, 1999). O objetivo deste trabalho foi quantificar a cinética de liberação de potássio induzida pela ação do ácido oxálico, nas frações granulométricas de um planossolo utilizado no cultivo de arroz irrigado por alagamento e descrever a liberação do potássio do solo pela equação parabólica de difusão.

\section{MATERIAL E MÉTODOS}

O estudo foi realizado em laboratórios do Departamento de Solos da Faculdade de Agronomia da Universidade Federal do Rio Grande do Sul, no período de fevereiro a julho de 1997. Foi utilizada amostra superficial $(0-20 \mathrm{~cm})$ do horizonte A de um PLANOSSOLO HIDROMÓRFICO Eutrófico solódico, do município de Pelotas, RS, originado de sedimentos de granito. A análise deste solo apresentou $\mathrm{pH}$ em água 5,$1 ; 21 \mathrm{~g} \mathrm{~kg}^{-1}$ de matéria orgânica; CTC 63 mmolc kg-1 (TEDESCO et al., 1995). O fracionamento da amostra em areia $(0,05-$ $2 \mathrm{~mm})$, silte $(2-50 \mu \mathrm{m})$ e argila $(<2 \mu \mathrm{m})$, foi realizado pela dispersão com $\mathrm{NaOH} 0,1 \mathrm{~mol} \mathrm{~L}^{-1}$. A areia foi separada por peneira e as frações silte e argila por sedimentação natural da suspensão em meio líquido, com pH ajustado para 10 pela adição de $\mathrm{NaOH}$, conforme TANNER \& JACKSON (1947). Obtevese $490 \mathrm{~g} \mathrm{~kg}^{-1}$ de areia, $330 \mathrm{~g} \mathrm{~kg}^{-1}$ de silte e de $180 \mathrm{~g}$ $\mathrm{kg}^{-1}$ de argila Cada fração foi caracterizada quanto ao teores de potássio total e potássio não trocável, extraídos, respectivamente, com ácido fluorídrico concentrado e com ácido nítrico $\left(\mathrm{HNO}_{3}\right) 1 \mathrm{~mol} \mathrm{~L}^{-1}$ fervente (PRATT, 1973). Como ocorre perda da fração potássio trocável durante o processo de fracionamento, considerou-se o potássio extraído com o $\mathrm{HNO}_{3}$ como sendo a fração não trocável. Na tabela 1 são apresentadas algumas características
Tabela 1 - Algumas características do horizonte A $(0-20 \mathrm{~cm})$ do Planossolo Hidromórfico.

\begin{tabular}{|c|c|}
\hline Material de origem & Sedimentos de granito \\
\hline $\begin{array}{l}\text { Minerais fontes de potássio } \\
\text { identificados por DRX }\end{array}$ & $\begin{array}{l}\text { Feldspatos, micas, } \\
\text { micas-esmectita }\end{array}$ \\
\hline Areia, $\mathrm{g} \mathrm{kg}^{-1}$ & 490 \\
\hline Silte, $\mathrm{g} \mathrm{kg}^{-1}$ & 330 \\
\hline Argila, $\mathrm{g} \mathrm{kg}^{-1}$ & 180 \\
\hline pH água & 5,1 \\
\hline Matéria orgânica, $\mathrm{g} \mathrm{kg}^{-1}$ & 21 \\
\hline $\mathrm{CTC}, \mathrm{mmol}_{\mathrm{c}} \mathrm{kg}^{-1}$ & 63 \\
\hline K-total $^{(1)}, \mathrm{mg} \mathrm{kg}^{-1}$ & 5.412 \\
\hline $\mathrm{K}-\mathrm{HNO}_{3}{ }^{(2)}, \mathrm{mg} \mathrm{kg}^{-1}$ & 84 \\
\hline K-não trocável ${ }^{(3)}, \mathrm{mg} \mathrm{kg}^{-1}$ & 49 \\
\hline K-trocável ${ }^{(4)}, \mathrm{mg} \mathrm{kg}^{-1}$ & 35 \\
\hline
\end{tabular}

(1) Extração com ácido fluorídrico concentrado e posterior dissolução em $\mathrm{HCl} 6$ mol L ${ }^{-1}$ (Pratt,1973). ${ }^{(2)}$ Extração com ácido nítrico $1 \mathrm{~mol} \mathrm{~L}^{-1}$, fervente (Pratt,1973). ${ }^{(3)}$ Calculado pela diferença $\mathrm{KHNO}_{3}-\mathrm{K}_{\text {trocável. }}{ }^{(4)}$ Extração com NH $\mathrm{NH}_{4} \mathrm{AOc} 1 \mathrm{~mol} \mathrm{~L}{ }^{-1}$, $\mathrm{pH} 7,0$.

selecionadas deste solo. A caracterização mineralógica, das frações areia, silte e argila, encontra-se detalhada em CASTILHOS (1999).

A cinética de liberação de potássio foi quantificada usando-se extrações seqüenciais com ácido oxálico $0,01 \mathrm{~mol} \mathrm{~L} \mathrm{~L}^{-1}$. Em tubos de centrífuga de 30ml, foram colocadas, em duplicatas, separadamente, $2,00 \mathrm{~g}$ de areia, de silte e de argila e, adicionado, sobre estas, $20 \mathrm{ml}$ de ácido oxálico 0,01M (relação 1:10). Na primeira extração, o tempo de contato e de agitação foi de uma hora, em agitador mecânico horizontal, com 110-120 oscilações por minuto. As soluções foram centrifugadas e o potássio no sobrenadante foi determinado por fotometria de chama. Às amostras remanescentes nos tubos de centrífuga, adicionaramse novas alíquotas de $20 \mathrm{ml}$ do mesmo ácido, repetindo-se esse procedimento até um total de 15 extrações. A cada reposição da solução extratora, os tubos foram agitados por 2 horas em agitador mecânico horizontal, na mesma velocidade descrita anteriormente e, depois, manualmente, uma vez ao dia. O tempo de contato de cada extração foi variável $(1,16,29,113,168,164,168,164,163$, 197, 210, 312, 312, 528 e 864 horas), totalizando 3.409 horas. A quantidade cumulativa de potássio liberada, bem como o tempo de equilíbrio acumulado foram calculados somando-se as horas e as quantidades de potássio liberadas a cada extração. O potássio liberado, cumulativamente, das frações areia, silte e argila foi relacionado com o tempo de equilíbrio. 
A relação entre a quantidade acumulada de potássio dessorvido das frações areia, silte e argila com o tempo de equilíbrio foi descrita pela equação parabólica de difusão [Kt $\left.\mathrm{K} \alpha^{-1}=\mathrm{a}+\mathrm{b}^{1 / 2}\right]$, onde $\mathrm{Kt}$ representa $\mathrm{a}$ quantidade de potássio liberado no tempo $t$ e $\mathrm{K} \alpha$ o potássio acumulado liberado até 3.409 horas.

\section{RESULTADOS E DISCUSSÃO}

Durante os períodos de equilíbrio das frações granulométricas do Planossolo com o ácido oxálico, ocorreram diferentes fases de liberação do nutriente (Figura 1). Este comportamento multifásico, também foi observado por outros pesquisadores (SONG \& HUANG, 1988; SIMARD $\boldsymbol{e} \boldsymbol{t} \boldsymbol{a l}$., 1992; MARTIN \& SPARKS, 1993) e, provavelmente, ocorreu em função da diversidade de tipos de minerais fontes de potássio neste solo, feldspatos, micas e interestratificados mica-esmectita e de sua distribuição nas frações granulométricas (CASTILHOS, 1999). Estes minerais, além de apresentarem sítios de adsorção com diferentes afinidades pelo potássio, liberam este nutriente com taxas diferenciadas (SONG \& HUANG, 1988). A areia foi a fração que liberou a menor quantidade de potássio, o que pode ser explicado pelos menores teores de potássio total e não trocável (Tabela 2) e da sua mineralogia mais pobre em minerais potássicos (CASTILHOS, 1999), constituída predominantemente pelo mineral quartzo (Tabela 1 ). A fração silte, apesar de possuir maior quantidade de $\mathrm{K}$ total, liberou menos potássio que a fração argila, o que pode ser atribuído a sua menor quantidade de potássio não trocável (Tabela 2) e, também, à

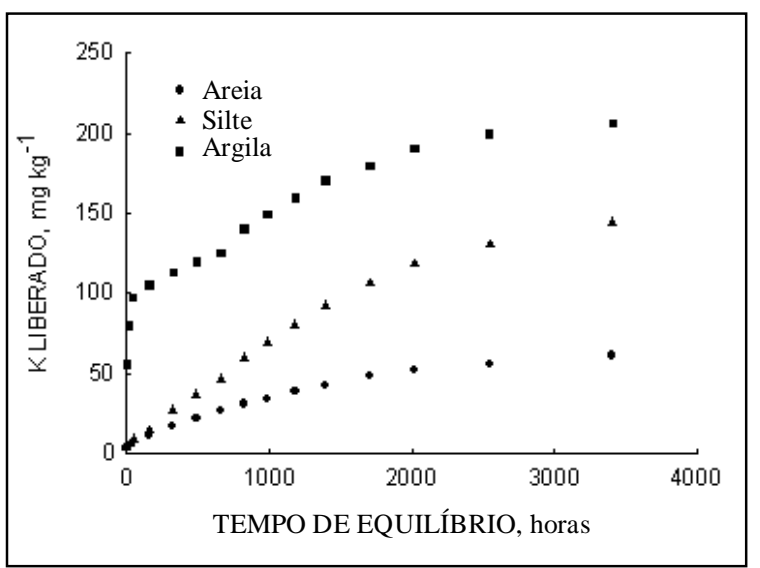

Figura 1 - Liberação cumulativa de potássio das frações granulométricas do Planossolo em função do tempo de equilíbrio com ácido axálico $0,01 \mathrm{~mol} \mathrm{~L}^{-1}$.
Tabela 2 - Teores de potássio total e não trocável e liberado das frações areia , silte e argila do horizonte A $(0-20 \mathrm{~cm})$ do Planossolo Hidromórfico.

\begin{tabular}{lccc}
\hline Característica & Areia & Silte & Argila \\
\hline & ----------------- m kg $^{-1}$ & \\
K total $^{(1)}$ & 2887 & 9081 & 5584 \\
K não trocável $^{(2)}$ & 24 & 41 & 276 \\
K liberado até $_{3409 \text { hs }^{(3)}}$ & 61 & 144 & 206 \\
Minerais fontes $_{\text {de K }}^{(4)}$ & $\begin{array}{c}\text { Feldspatos, } \\
\text { micas }\end{array}$ & $\begin{array}{c}\text { Feldspatos, micas, } \\
\text { mica-esmectita }\end{array}$ & $\begin{array}{c}\text { Feldspatos, micas, } \\
\text { mica-esmectita }\end{array}$ \\
\hline
\end{tabular}

${ }^{(1)}$ Extração com ácido fluorídrico concentrado e dissolução com $\mathrm{HCl}$ 6mol $\mathrm{L}^{-1}$. ${ }^{(2)}$ Extração com $\mathrm{HNO}_{3} 1 \mathrm{~mol} \mathrm{~L}{ }^{-1}$, fervente ${ }^{(3)}$ Extrações sucessivas com ácido oxálico $0,01 \mathrm{~mol} \mathrm{~L}^{-1}$. ${ }^{(4)}$ Castilhos, (1999)

presença de menores quantidades de mica e interestratificados mica-esmectitas, em relação à fração argila. A quantidade de $\mathrm{K}$ não trocável extraídas pelo ácido oxálico no silte e na areia foram mais elevadas do que as extraídas com ácido nítrico, demonstrando que, possivelmente, houve liberação de $\mathrm{K}$ da forma estrutural destas frações.

A argila liberou maior quantidade de potássio do que as duas outras frações, especialmente na fase inicial (nas primeiras 46 horas de equilíbrio) na qual a quantidade de potássio liberada correspondeu a $47 \%$ da quantidade total liberada nas 3.409 horas de equilíbrio (Figuras 1 e 2). Esse comportamento poderia ser justificado pelas seguintes hipóteses: o potássio liberado mais rapidamente seria proveniente de sítios de adsorção menos específicos, situados nas entrecamadas dos minerais 2:1, porém, próximo das bordas, ou da superfície das partículas de feldspatos, minerais que

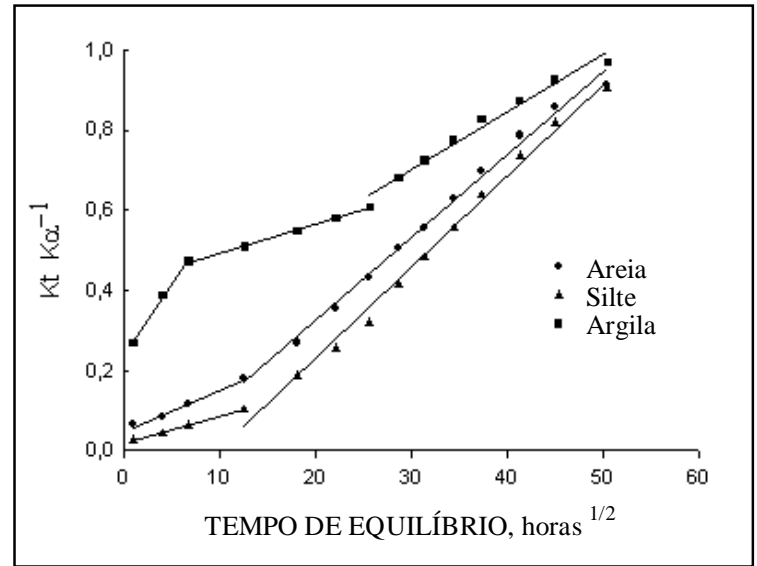

Figura 2 - Cinética da liberação de potássio das frações granulométricas do Planossolo Hidromórfico descrita pela equação parabólica de difusão. 
também foram encontrados nesta fração (CASTILHOS 1999), que estaria mais acessível ao extrator. Na medida em que o tempo de extração foi aumentando, o intemperismo, provocado pela ação do ácido oxálico, nos minerais 2:1, avançou em direção ao centro das partículas, em que o potássio é retido mais fortemente, o que ocasionou um decréscimo acentuado na taxa de liberação deste nutriente. Esta passou então a ser controlada pela taxa de difusão do potássio, nas entrecamadas do centro das partículas em direção às bordas externas dos minerais, parcialmente intemperizados. Após a liberação rápida do potássio dos sítios mais externos dos feldspatos, a liberação adicional deste nutriente, dos sítios internos, só ocorrerá se houver quebra da estabilidade das ligações $\mathrm{Al}-\mathrm{O}$ e Si-O, através das reações de protonação e complexação pelo ácido oxálico, o que aconteceria mais lentamente, devido à proteção exercida pela fina camada de $\mathrm{Si}-\mathrm{Al}-\mathrm{O}$, que normalmente se forma em torno do mineral, durante sua intemperização, dificultando o acesso do extrator (RICH, 1968). Outra justificativa para a maior liberação inicial seria a possibilidade da estrutura dos minerais sofrer algum tipo de dano, próximo à superfície das partículas, durante o processo de preparação das amostras (fracionamento). Esses danos, poderiam facilitar o acesso ao potássio situado nas entrecamadas da mica ou no interstício dos feldspatos, tornado-os mais suscetíveis à ação do extrator (SONG \& HUANG, 1988). Na argila, as quantidades totais de potássio liberadas pelo ácido oxálico $0,01 \mathrm{~mol} \mathrm{~L}^{-1}$ foram inferiores às quantidades extraídas com $\mathrm{HNO}_{3} 1 \mathrm{~mol} \mathrm{~L}^{-1}$ fervente (Tabela 2). Devido ao menor tamanho e à grande superfície específica dos minerais nesta fração, pode ter ocorrido destruição destes, pelo ácido nítrico fervente, que é um ácido forte, justificando os maiores teores de $\mathrm{K}$ liberados, por este extrator, em relação ao ácido oxálico. Resultados semelhantes foram observados, para a fração argila em solos do Canadá, em que uma única extração de potássio, com $\mathrm{HNO}_{3} 1 \mathrm{~mol} \mathrm{~L}^{-1}$ fervente, liberou mais potássio do que a extração acumulada em 3.200 horas, com ácido cítrico $5 \times 10^{-4} \mathrm{~mol} \mathrm{~L}^{-1}$ (SIMARD et al., 1992).

A descrição da cinética de liberação do potássio (Figura 2) pela equação parabólica de difusão (FEIGENBAUM et al., 1981) indicou que, para as frações areia e silte, a liberação do potássio ocorreu em duas fases distintas e, para fração argila, em três fases, com diferentes taxas de velocidade (Tabela 3, coeficiente angular). As taxas de liberação do potássio das frações areia $\left(2,07 \times 10^{-2} \mathrm{~h}^{-1}\right)$ e silte $\left(2,27 \times 10^{-2} \mathrm{~h}^{-1}\right)$, na segunda fase, foram similares e maiores que as da primeira
Tabela 3 - Coeficientes da equação parabólica de difusão (Kt $\left.\mathrm{K} \alpha^{-1}=\mathrm{a}+\mathrm{bt}^{1 / 2}\right)$ para as diferentes fases de liberação de potássio nas frações granulométricas do Planossolo Hidromórfico.

\begin{tabular}{llclc}
\hline \multirow{2}{*}{ Fração } & & \multicolumn{3}{c}{ Coeficientes } \\
\hline \multirow{4}{*}{ Areia } & & Linear & Angular & $\mathrm{r}$ \\
& $1^{\text {a }}$ fase & $4,85 \times 10^{-2}$ & $1,02 \times 10^{-2}$ & $0,992^{*} *$ \\
\multirow{3}{*}{ Silte } & $2^{\text {a }}$ fase & $9,05 \times 10^{-2}$ & $2,07 \times 10^{-2}$ & $0,997 * *$ \\
& $1^{\text {a }}$ fase & $1,89 \times 10^{-2}$ & $0,65 \times 10^{-2}$ & $0,997 *$ \\
& $2^{\text {a }}$ fase & $-2,24 \times 10^{-1}$ & $2,27 \times 10^{-2}$ & $0,996^{*} *$ \\
& $1^{\text {a }}$ fase & $2,37 \times 10^{-1}$ & $3,55 \times 10^{-2}$ & $0,999 * *$ \\
& $2^{\text {a }}$ fase & $4,23 \times 10^{-1}$ & $0,71 \times 10^{-2}$ & $0,999 * *$ \\
& $3^{\text {a }}$ fase & $2,64 \times 10^{-1}$ & $1,45 \times 10^{-2}$ & $0,988^{* *}$ \\
& & & &
\end{tabular}

fase. $\mathrm{Na}$ fração argila, ocorreu a maior taxa de liberação, de $3,55 \times 10^{-2} \mathrm{~h}^{-1}$, nas primeiras 46 horas de equilíbrio, seguindo-se uma liberação a uma taxa bem menor, de $0,71 \times 10^{-2} \mathrm{~h}^{-1}$, aumentando, novamente, na fase subseqüente. As diferentes fases e taxas de liberação do potássio das frações granulométricas desse solos, podem ser atribuídas às diferentes quantidades de K-total e pelos minerais fontes de potássio que ocorrem em cada fração. Nas frações areia e silte os minerais fontes de potássio identificados foram micas e significativas quantidades de feldspatos; na fração argila foram identificados feldspatos, micas e esmectitas (CASTILHOS, 1999).

A quantidade de potássio liberada no Planossolo, pela ação do ácido oxálico $0,01 \mathrm{~mol} \mathrm{~L}^{-1}$, após 3.409 horas de equilíbrio, foi de $37,06 \mathrm{mg}$ de $\mathrm{K}$ $\mathrm{kg}^{-1}$ pela fração argila (32\%), de $47,67 \mathrm{mg} \mathrm{de} \mathrm{K} \mathrm{kg}^{-1}$ pela fração silte $(42 \%)$ e de $29,96 \mathrm{mg} \mathrm{K} \mathrm{kg}^{-1}$ na fração areia (26\%), totalizando $114,69 \mathrm{mg} \mathrm{K} \mathrm{kg}^{-1}$ de solo, o que corresponde a somente $2,1 \%$ do teor de K-total encontrado nesse solo (Tabela 1). Esta quantidade foi maior do que a extraída pelo ácido nítrico $1 \mathrm{~mol} \mathrm{~L}^{-1}$ fervente (Tabela 1), o que sugere que o ácido oxálico, além do K-não trocável, induziu a liberação de potássio estrutural dos minerais nesse solo. Resultados semelhantes foram obtidos por MEHTA et al. (1995) para quatro solos da Índia, que também obtiveram uma maior extração de potássio com ácido oxálico em relação ao ácido cítrico ou ácido nítrico, nas mesmas concentrações. As diferenças nas quantidades extraídas foram atribuídas às quantidade de íons $\mathrm{H}^{+} \mathrm{e}$ de ligantes dos ácidos orgânicos e às diferenças na capacidade de complexação dos ligantes. Os íons $\mathrm{H}^{+}$podem deslocar os íons $\mathrm{K}^{+}$e também desestabilizar a estrutura dos minerais pela sua incorporação aos oxigênios apicais da lâmina tetraedral, reduzindo a carga desta camada (DATTA \& SASTRY, 1993). Para os ácidos orgânicos, além da ação dos íons $\mathrm{H}^{+}$, 
deve ser considerado, também, o efeito adicional dos ligantes orgânicos, cujos grupos $\mathrm{OH}$ e $\mathrm{COOH}$ tendem a formar complexos com os cátions da solução e da estrutura dos minerais, acelerando a sua decomposição (SONG \& HUANG 1988).

\section{CONCLUSÕES}

O ácido oxálico induziu a liberação de potássio das frações areia, silte e argila do Planossolo, que decresceram, quantitativamente, na sequência silte $>$ argila $>$ areia.

A descrição da cinética de liberação do potássio pela equação parabólica de difusão mostrou que o processo ocorreu, a diferentes velocidades, em duas fases, para as frações areia e silte e, em três fases, para a fração argila.

As quantidades de potássio liberadas do Planossolo, considerando a participação de cada fração e o respectivo porcentual de ocorrência no solo, representaram somente $2,1 \%$ do K-total solo.

\section{REFERÊNCIAS BIBLIOGRÁFICAS}

CASTILHOS, R.M.V. Suprimento de potássio em solos cultivados com arroz irrigado e sua relação com mineralogia, formas e cinética de liberação. Porto Alegre, 1999. 175p. Tese (Doutorado em Ciência do Solo) Programa de Pós-graduação em Ciência do Solo, Faculdade de Agronomia, Universidade Federal do Rio Grande do Sul, Porto Alegre, 1999.

COX, A.E., JOERN B.C., ROTH C.B. Nonexchangeable ammonium and potassium determination in soils with a modified sodium tetraphenylboron method. Soil Science Society America Journal, Madison, v.60, p.114-120, 1996.

DATTA, S.C., SASTRY, T.G. Potassium release in relation to mineralogy of silt and clays. Journal of the Indian Society of Soil Science, New Delhi, v.41, n.3, p.452-458, 1993

DAY, P. Particle fractionation and particle-size analysis. In: BLACK, C.A., (ed.) Methods of soil analysis. Madison : America Society of Agronomy, 1965. p.545-567 (Agronomy Series, 9).

DILLON, S.K., DHILLON, K.S. Kinetics of release of nonexchangeable potassium by cation saturated resins from red (Alfisols), black (Vertisols) and alluvial (Inceptisols) of India. Geoderma, Amsterdam, v.47, p.283-300, 1990

FEIGENBAUM, S., EDELSTEIN, R., SHAINBERG, I. Release rate of potassium and structural cations from micas to ion exchangers in dilute solutions. Soil Science Society of America Journal, Madison, v.45, p.501-506, 1981.

LOPES, S.I.G. Calibração de análise de solo para arroz irrigado. In: REUNIÃO DA CULTURA DO ARROZ IRRIGADO, 18 , 1989, Porto Alegre. Anais... Porto Alegre: IRGA, 1989. p.191-201.

MACHADO, M.O., FRANCO, J.C.B. Parcelamento da adubação potássica em arroz pré-germinado, no solo Pelotas
(Planossolo). In: REUNIÃO DA CULTURA DO ARROZ IRRIGADO, 21, 1995, Porto Alegre. Anais... Porto Alegre : IRGA, 1995. p.177-180.

MARTIN, H.W., SPARKS, D.L. On the behavior of nonexchangeable potassium. Communication in Soil Science and Plant Analysis, New York, v.16, n.2, p.133$162,1985$.

MEHTA, S.C., MEEL,K.S., GREWAL E.A. Release of nonexchangeable potassium in Entisols. Journal of the Indian Society of Soil Science, New Delhi, n.43, v.3, p.351-356, 1995.

MEURER, E.J., ROSSO,J.I. Cinética de liberação de potássio em solos do Rio Grande do Sul. Revista Brasileira de Ciência do Solo, Viçosa, n.21, p.553-558, 1997.

MUNN, D.A., WILDING, L.P., McLEAN, E.O. Potassium release from sand, silt and clay soil separates. Soil Science Society of America Journal, Madison, n.40, p.364-366, 1976.

PRATT, P.F. Potassium. In: BLACK, C.A. Methods of soil analysis. Part 1. Madison: American Society of Agronomy, 1973. p.1022-1032. (Agronony Series, 9).

RICH, C.I. Mineralogy of soil potassium. In: KILMER, V.J.; YOUNTS, S.E., BRADY, N.C. (Eds.). The role of potassium in agriculture. Madison : American Society of Agronomy, 1968. p.79-108.

SILVA, A.V., GUILHERME, L.R.G., NOGUEIRA, F.D. $\boldsymbol{e}$ t $\boldsymbol{a}$ l. Cinética de liberação de potássio em solos cultivados com cafeeiro: Efeito de ácidos orgânicos. In: REUNIÃO BRASILEIRA DE FERTILIDADE DO SOLOS E NUTRIÇÃO DE PLANTAS, 1998, Caxambú. Resumos... Lavras : UFLA/SBCS/SBM, 1998. p.753.

SIMARD, R.R., KIMPE,C.R., ZIZKA, J. Release of potassium and magnesium from soil fractions and it kinetics. Soil Science Society of America Journal, Madison, v.56, p.14211428, 1992.

SIMONETE, M.A. Efeito residual da adubação potássica do azevém sobre o arroz subseqüente em plantio direto. Pelotas, RS, 1998. 40p. Dissertação (Mestrado Agronomia Solos) - Faculdade de Agronomia Eliseu Maciel, Universidade Federal de Pelotas, Pelotas, 1998.

SONG, S.K., HUANG, P.M. Dynamics of potassium release from potassium-bearing minerals as influenced by oxalic and citric acids. Soil Science Society of America Journal, Madison, v.52, p.383-390, 1988.

TAM, K.H. Degradation of soil minerals by organic acids. In: HUANG, P.M., SCHNITZER, M. (ed.). Interactions of soil minerals with natural organics and microbes. Madison : Soil. Science Society of America, 1986. 606p.

TANNER, C.B., JACKSON, M.L. Nomographs of sedimentation times for soil particles under gravity or centrifugal acceleration. Soil Science Society of America Proceedings, Madison, v.12, p.60-65, 1947.

TEDESCO, M.J., GIANELlO,C., BISSANI, C.A. et al. Análise de solos, plantas e outros materiais. 2.ed. Porto Alegre : UFRGS, 1995. 174p. (Boletim Técnico ,5). 